\title{
BUKU INFORMASI SRABAD SEBAGAI EKSPRESI SENI MASYARAKAT ISLAM CIREBON
}

\author{
Inez Meirina Savitri ${ }^{1)}$, Puri Kurniasih ${ }^{2)}$, Dendi Pratama ${ }^{2)}$ \\ Program Studi Desain Komunikasi Visual, \\ Fakultas Bahasa dan Seni, Universitas Indraprasta PGRI \\ Jl. Nangka No. 58 C, Tanjung Barat, Jakarta 12530, Indonesia \\ inezmeirina@gmail.com
}

\begin{abstract}
Abstrak
Srabad merupakan pengabungan gambar figur dengan tulisan kaligrafi sebagai bingkainya. Buku informasi srabad ini dirancang dengan tujuan sebagai upaya melestarikan dan mewariskan budaya Cirebon dalam bentuk buku informasi yang dapat digunakan sebagai media pembelajaran serta dapat dijadikan referensi, sehingga dapat menambah wawasan tentang budaya tradisi khususnya di Cirebon. Metode penelitian yang digunakan dalam penelitian ini adalah metode kualitatif deskriptif. Pengumpulan data melalui studi literatur, observasi dan wawancara yang berhubungan dengan srabad, untuk melakukan analisa data pustaka dan data lapangan. Hasil yang dicapai adalah membuat buku informasi tentang srabad Cirebon sebagai referensi yang berisi penjelasan secara rinci.
\end{abstract}

Kata Kunci: Srabad, Lukisan Kaca, Cirebon

\begin{abstract}
Srabad is a combination of figures with calligraphic writing as a frame. This srabad information book was designed with the aim of preserving and passing down Cirebon culture in the form of an information book that can be used as a learning medium and can be used as a reference so that it can add insight into traditional culture especially in Cirebon. The research method used in this research is the descriptive qualitative method. Data collection through literature studies, and interviews related to srabad, to analyze library data and field data. The results achieved when making an information book about srabad Cirebon as a reference containing a detailed explanation.
\end{abstract}

Keywords: Srabad, Glass Painting, Cirebon

\section{PENDAHULUAN}

Masuknya Islam di pulau Jawa memiliki kontribusi besar pada perkembangan di bidang seni. Dengan diterimanya agama Islam oleh masyarakat, terjadi penyerapan bentuk-bentuk serta gayagaya artistik Islam. Namun, hal tersebut tidak mengubah identitas tradisi budaya pra-Islam setempat. Di beberapa tempat masih menggunakan bentuk dan gaya dari masa sebelum islamisasi berlangsung. Seperti halnya pada pintu masuk menuju komplek Keraton Kasepuhan di Cirebon, masih mempergunakan gaya Hindu.

Penyebaran agama Islam di Cirebon selain dilakukan melalui misi keagamaan yang berpusat di pesantren, tetapi juga dilakukan melalui misi kebudayaan. Para pemuka agama melakukan dakwah menggunakan lambang-lambang budaya. Pemuka agama memanfaatkan 
lambang budaya yang kemudian dipadukan dengan muatan ajaran Islam sehingga mudah dicerna dan diterima oleh masyarakat. Cara ini dinilai ampuh untuk mendapat simpati masyarakat.

Di Indonesia, kaligrafi Islam menjadi elemen penting di dalam seni dekoratif Islam. Kaligrafi juga dibubuhkan pada benda-benda seperti pedang, tombak, umbul-umbul serta bendera pataka (panji-panji) kerajaan. Selain itu kaligrafi juga muncul pada lukisan kaca dan lukisan batik yang memberi gambaran tentang seni lukis Islam dan ukiran kayu sebagai benda dekoratif- magis.

Di Cirebon lukisan kaca menjadi hiasan di dalam keraton. Tema tradisional lukisan kaca Cirebon seperti tema-tema dakwah Islam berupa kaligrafi dan pewayangan, burak, dan masjid. Tokoh lain yang sering ditampilkan dalam kaligrafi adalah Macan Ali sebagai lambang kecirebonan dan Srabad, yaitu binatang campuran yang nampaknya dipengaruhi oleh bentuk figur kereta Paksinagaliman atau Ken Singabarong (Budiono, 2002: 8). Srabad merupakan pengabungan tulisan Arab dengan gambar figur yang sebagai bingkainya. Tema Srabad berupa lukisan yang menggunakan gambar hewan mitologi Hindu, yaitu Ganesha yang merupakan hewan gajah. Gambar ganesha dibuat menjadi kerangka dari kaligrafi yang berisi doa-doa, dipercaya sebagai penolak bala (Wulandari, 2012: 4). Ide dalam membuat srabad dimaknai sebagai simbol spiritual masyarakat Cirebon, kemudian ide itu terus diwariskan melalui bentuk kesenian, sehingga tema srabad memberi pengaruh besar dalam perkembangan seni rupa tradisi. Srabad yang dalam penciptaannya memiliki aturan-aturan tertentu. Dalam perkembangannya objek utama dibentuk dengan kaligrafi Arab, sedangkan objek penunjangnya dihiasi motif-motif khas Cirebon.

Melihat dari persoalan tersebut, peneliti mengganggap perlu untuk mengangkat persoalanpersoalan makna pada Srabad menjadi sesuatu yang dapat dijadikan bahan penelitian. Peneliti kemudian melakukan proses pengumpulan data berkaitan dengan srabad. Tujuan penelitian ini sebagai penelitian ilmiah, yaitu mendapatkan pemahaman untuk mendeskripsikan makna yang ada pada ragam hias srabad sebagai ekspresi seni masyarakat Islam di Cirebon. Selain itu, belum tersedianya media buku informasi tentang budaya tradisi. Oleh karena itu, dibutuhkan media berupa buku informasi mengenai Srabad Cirebon sebagai alternatif media informasi sebagai referensi untuk menambah wawasan. Penelitian ini berharap nilai toleransi dan spiritual yang ada pada srabad dapat diterapkan pada masyarakat dalam upaya menjaga keberagaman budaya yang ada.

\section{METODE PENELITIAN}

\section{A. Waktu dan Tempat Penelitian}

Waktu penelitian dilaksanakan sejak bulan Mei 2018 sampai dengan waktu yang belum ditentukan. Tempat penelitian dilakukan di wilayah Jakarta dan Cirebon. Peneliti mendatangi Keraton Kasepuhan dan Keraton Kacirebonan di Cirebon. Selain itu, juga mengunjungi rumah budaya Pesambangan Jati di Cirebon. Peneliti juga mendatangi Perpustakaan Nasional Republik Indonesia dan Museum Tekstil di Jakarta. Adapun data penelitian didapat dari proses studi pustaka, observasi, dan wawancara.

\section{B. METODE PENELITIAN}

Dalam penelitian ini metode yang digunakan adalah metode kualitatif deskriptif, karena penelitian ini dilakukan dengan cara melakukan observasi atau pengamatan secara interaktif dan melakukan wawancara pada sumber-sumber yang kompeten pada obyek yang diteliti. Sehingga menghasilkan data deskriptif berupa kata-kata tulisan atau lisan dari orang-orang dan prilaku yang diamati di lapangan. Informasi juga diperoleh melalui penelusuran literatur. Dengan menggunakan metode kualitatif deskriptif ini, maka dapat diketahui bentuk ragam hias pada srabad serta maknanya.

Untuk memperoleh data, peneliti menggunakan metode yang disesuaikan pada jenis penelitian kualitatif dengan cara, antara lain:

\section{Studi Pustaka}


Dari data yang didapat, peneliti menggunakan jenis penelitian kualitatif yaitu studi kepustakaan, metode pengumpulan data yang menggunakan referensi buku, jurnal, dan website yang berkaitan dengan materi yang mendukung penelitian.

\section{Observasi}

Peneliti juga melakukan observasi dalam mengumpulkan data yang diperlukan untuk melengkapi data yang sudah diperoleh. Peneliti melakukan observasi pada bulan Mei 2018. Observasi ini dilakukan dengan mengunjungi Keraton Kasepuhan, dan Keraton Kacirebonan di Cirebon untuk mendokumentasikan foto-foto srabad yang ada di keraton tersebut. Selain itu juga mengunjungi rumah budaya Pesambangan Jati untuk melihat naskah-naskah kuno.

\section{Wawancara}

Wawancara dilakukan oleh peneliti dengan narasumber yang kepakarannya terkait objek penelitian. Pertama dengan bapak Muhamad Mukhtar Zaedin selaku ketua bidang pemanfaatan di pusat naskah klasik. Wawancara tersebut bertujuan untuk mengetahui informasi tentang pengertian srabad. Kedua, Dr. Raden Opan Safari Hasyim, selaku budayawan dan seniman lukis kaca. Wawancara tersebut bertujuan untuk mengetahui informasi tentang srabad dan ragam hias yang ada di srabad.

\section{HASIL DAN PEMBAHASAN}

1. Kesenian Islam

Menurut Geertz dalam Sucitra (2015: 90) menjelaskan bahwa manusia merupakan makhluk yang bergantung pada jaringan-jaringan (sistemik) makna yang ditenunnya sendiri, kebudayaan adalah jaringan makna-makna tersebut. Manusia yang berkebudayaan dapat dipastikan bahwa budaya yang diwarisi saat ini merupakan suatu bentuk yang lahir melalui proses panjang sejak masa lampau (Bahar, 2009:147). Di sisi lain Gustami (dalam Sucitra, 2015: 90) memaparkan kedatangan Islam ke Asia Tenggara diperkirakan sudah berlangsung antara abad ke-11 hingga ke-12. Islam diperkirakan masuk Indonesia pada abad ke-11 melalui Serambi Mekah, Aceh. Selanjutnya Islam menyebar sampai ke pulau Jawa pada abad ke-13 oleh para musafir melalui kota perdagangan di sepanjang pantai utara Jawa, seperti Surabaya, Gresik, Tuban, Lasem, Kudus, Demak. Menurut Hadi dalam Sucitra (2015: 91), Agama dan seni secara empiris mempunyai hubungan yang erat pada mulanya, karena agama dan seni mempunyai unsur yang sama yaitu ritual dan emosi. Ritual merupakan transformasi simbolis dan ungkapan perasaan dari pengalaman manusia dan hasil akhir dari artikulasi yang demikian itu merupakan emosi yang spontan dan kompleks.

Seni Islam menurut Nasr (Siti Binti A.Z., 2005) setidaknya mengandung tiga hal, (1) mencerminkan nilai-nilai religius sehingga tidak ada yang disebut seni sekuler. Tidak ada dikotomi religius dan sekuler dalam Islam. Kekuatan atau unsur sekuler dalam masyarakat Islam selalu memiliki pengertian religius seperti halnya hukum Ilahi yang secara spesifik memiliki unsur-unsur religius. (2) Menjelaskan kualitas-kualitas spiritual yang bersifat santun akibat pengaruh nilai-nilai sufisme. (3) Ada hubungan yang halus dan saling melengkapi antara masjid dan istana dalam hal perlindungan, penggunaan, dan fungsi berbagai seni.

Sepintas dalam sejarah kebudayaan Islam melahirkan sedikit sekali karya-karya seni rupa dan karenanya sebagai gantinya melahirkan karya-karya kaligrafi dan arsitektur (Sahid, 2004: 81). Islam tidak melarang umat Islam untuk berkesenian, asalkan dengan syarat bahwa seni harus takwa, dan konsekuen antara ucapan dan perbuatan. Dalam hal ini harus diingat bahwa sebebas-bebasnya kreativitas tetap ada batasnya. Pembatasan tersebut berupa hati nurani manusia (moral) atau dalam istilah Islam disebut akhlak. Kreativitas seni harus menjadi bagian moral yang pola dasarnya telah ditentukan oleh agama, Sahid dalam Sucitra (2015: 94). Dalam musyawarah seniman budayawan Islam di Jakarta (1961) yang diketuai sastrawan dan ulama besar Hamka antara lain merumuskan bahwa kesenian itu hukumnya halal. Penyair Taufik Ismail dalam Sucitra (2015: 95) mengatakan bahwa karya yang 
menyuarakan nafas Islam adalah karya yang senantiasa membuat orang selalu percaya kepada Allah. Kesenian Islam setidaknya harus memiliki ciri-ciri: (1) mengandung nilai-nilai ketauhidan sehingga karya tersebut diharapkan dapat menumbuhkan dan meningkatkan keimanan seseorang kepada Allah Swt.; (2) menyiratkan ajaran akhlaqul qarimah (akhlak mulia) sehingga melalui karya seni bisa mendorong seseorang untuk meningkatkan perwujudan akhlak mulia dalam kehidupannya.; (3) mengungkapkan pesan-pesan yang berkaitan dengan tata aturan hukum yang ditetapkan dalam Islam; (4) kebebasan dalam berkreasi dibatasi dengan hati nurani (akhlak) sehingga dalam kesenian Islam tidak dikenal pengorbanan nilai-nilai ketauhidan dan akhlak mulia demi pemujaan kebebasan kreativitas; dan (5) kesenian Islam sudah semestinya hanya diciptakan oleh orang yang beragama Islam, bukan agama yang lain (Sahid dalam Sucitra 2015 : 95).

Karya seni yang tidak kalah indahnya mendapatkan sentuhan tradisi Islami di Jawa adalah lukisan kaca. Lukisan kaca ini diperkaya dengan kaligrafi Arab sebagai ornamentik pelengkap bentuk utama yang diambil dari Alquran yaitu berisi cerita-cerita Islami serta sebagai media pengenalan dan penyebaran agama Islam di Indonesia (Fisher, 1994:47). Pemahaman ini berlaku juga dalam lukisan kaca yang terdapat di Istana Kasepuhan Cirebon dengan sebutan Macan Ali. Macan Ali adalah lukisan kaca yang digubah dengan aksara Arab yang membentuk wujud macan sebagai lambang Kerajaan Kasepuhan. Lukisan kaca sebagai karya lukisan klasik berkembang terus dengan mengambil motif wayang sebagai pokok lukisan yang dibentuk dengan rangkaian kalimat doa dari ayat suci Alquran. Tokoh yang sering ditampilkan dalam kaligrafi adalah Macan Ali sebagai lambang kecirebonan. Awalnya srabad merupakan sarana syiar agama Islam, hal tersebut terlihat dari digunakannya tulisantulisan Arab yang diambil dari ayat-ayat Alquran. Menurut Budiono (2002: 8), Tulisan kaligrafi dapat dibagi menjadi dua:

a. Kaligrafi yang hanya menonjolkan tulisan Arab yang disertai dengan motif wadasan, mega mendung, motif sulur atau dedaunan. Ayat-ayat Alquran yang dipakai seperti ayat Qursi, surat Al-Fatihah, Syahadat, dan Basmalah.

b. Kaligrafi dengan tulisan Arab yang meminjam figur wayang sebagai bentukan kaligrafi. Motif-motif wadasan dan mega mendung tetap menyertai penggayaannya sebagai pelengkap. Figur wayang yang sering digunakan yaitu Semar, Betara Narada, Betara Guru. Tokoh lain yang sering digunakan yaitu macan ali sebagai simbol kecirebonan.

Bentuk samar dari wayang yang divisualisasikan hanya sebagai kerangka kaligrafinya bukan tanpa sebab, ini karena dalam Islam adanya larangan menggambar makhluk hidup. Akhirnya wayang yang telah dimodifikasi sedemikian rupa oleh Sunan Kalijaga, hingga menghilangkan unsur-unsur makhluk hidup harus dimodifikasi ulang menjadi samar-samar, tentunya dengan pesan dan makna yang lebih dalam (Fathurrohman, 2002: 45).

Dari yang awalnya srabad merupakan sarana syiar Islam menjadi berubah dan dipandang sebagai sarana penyampaian ekspresi diri. Kebutuhan seniman yang dahulu adalah pendukung penyebaran agama, sekarang bergeser pada nilai-nilai kebutuhan yang sifatnya pragmatis.

\section{Bentuk Srabad}

Srabad dengan bentuk macan ali merupakan salah satu tema khas di Cirebon dan telah lama dikenal oleh masyarakat Cirebon. Macan ali merupakan hewan mistis yang dimiliki oleh kerajaan Padjajaran pada masa Hindu yang kemudian diadopsi oleh kesultanan Cirebon yang beragama Islam. Bentuk macan ali dibuat dari susunan kaligrafi dan macan ali sebagai kerangkanya, dimana bentuknya mengikuti aturan Islam pada masa itu yang mengubah bentuk makhluk hidup. Kaligrafinya sendiri dibentuk dari ayat Alquran yang berbunyi Laa ilaaha illallaah artinya Tiada Tuhan selain Allah, yang menjadi saah satu syahadat yang agung di Agama Islam (Wulandari, 2012: 6). Ayat-ayat Alquran yang terdapat di dalam 
macan ali menjadi salah satu pelindung dan penjaga batin manusia. Lukisan macan ali ini dahulu dipercaya sebagai tolak bala.

Kaligrafi Macan Ali digambarkan dengan warna emas yang memberi kesan mistis, anggun, dan tinggi. Pada beberapa kaligrafi Macan Ali untuk latar belakangnya unsur-unsur khas juga masih dimunculkan seperti motif wadasan dan mega mendung (Wulandari, 2012: 7).

Srabad dengan bentuk Semar sangat digemari oleh pelukis kaca. Semar menyatukan semua pertentangan dalam bentuknya, ia bukan pria ataupun wanita, ia tidak tertawa maupun menangis, bukan Tuhan maupun manusia, tidak memiliki tempat tinggal, tidak berkedudukan, tidak dekat maupun jauh, tetapi selalu hadir. Figur Semar digambaran tubuhnya berwarna hitam yang menurut filosofi wayang melambangkan keteguhan hati dengan muka berwarna putih dan mempertahankan bentuk dasar Semar Cirebon. Penampilan Semar tidak rupawan dan digambarkan sebagai manusia cebol berhidung pesek, dagu yang cameuh, mata lelah, gemuk, dan berpanat bulat. Posisi Semar yaitu tangan kanan naik sebahu, serta tangan kiri berada setinggi posisi perut (Wulandari, $201: 5$ ).

3. Buku Sebagai Media Informasi

Buku merupakan bentuk pengabadian sebuah karya, bisa berbentuk karya sastra, peraturan atau perundang-undangan. Menurut KBBI Daring (2016), buku adalah lembar kertas yang berjilid berisi tulisan atau kosong; kitab. Menurut Suprana (dalam Triguno, 2013), buku adalah suatu bentuk benda karya manusia yang berfungsi sebagai salah satu media komunikasi atau informasi. Buku saat ini masih menjadi prioritas utama untuk mencari informasi ditengah perkembangan teknologi yang semakin pesat.

Menurut Depdiknas (dalam Muhson, 2010), kata media berasal dari bahasa latin dan merupakan bentuk jamak dari kata medium yang secara harfiah berarti perantara atau pengantar. Makna umumnya adalah segala sesuatu yang dapat menyalurkan informasi dari sumber informasi kepada penerima informasi.

Buku adalah salah satu media komunikasi. Fungsi dari komunikasi di masyarakat menurut Lasswell dalam Choiriyah (2014: 130), menunjukkan empat fungsi, yaitu pengamatan terhadap lingkungan (the surveillance of the enviroment), penyingkapan ancaman dan kesempatan yang mempengaruhi nilai masyarakat dan bagian-bagian unsur di dalamnya, serta korelasi unsur-unsur masyarakat ketika menanggapi lingkungan (correlation of the components of society in the making a response of enviroment); Penyebaran warisan sosial (transmission of the social inheritance).

Buku adalah tempat pengumpulan masa lalu kita, serta agen pengembangan personal dan perubahan sosial. Sama seperti media lainnya, buku merupakan cerminan budaya, menurut Baran dalam Choiriyah (2014: 130). Selain itu, menurut Pakar dkk. (dalam Choiriyah, 2014: 130) buku juga mampu menyalurkan ilmu seseorang ke orang lain tanpa perlu bertatap muka.

Berdasarkan uraian tentang buku informasi di atas, media buku tersebut dapat diartikan sebagai alat, sarana atau perantara yang digunakan untuk menyampaikan warisan sosial yang dapat memberikan informasi tanpa perlu bertatap muka.

1. Warna

Dalam merancang buku informasi harus mempertimbangkan beberapa hal, yaitu:

Warna adalah sebuah spektrum tertentu terdapat di dalam cahaya yang sempurna/putih.

2. Garis

Garis menciptakan arah, gerak, dan energi. Garis tegas umumnya digunakan untuk menggambarkan fenomena alam, sedangkan garis lembut dapat menciptakan kesan feminim, melankolis ataupun kelunakan.

3. Ilustrasi

Ilustrasi secara umum berarti sebagai gambar yang menjelaskan atau menerangkan sesuatu yang berguna untuk merangsang daya tarik pembaca.

4. Tipografi 
Tipografi berperan sebagai penyampai pesan komunikasi. Huruf mempunyai dampak pada ruang dalam layout. Oleh karena itu, tipografi harus mampu berkomunikasi dalam bentuk yang paling jelas dan terbaca.

5. Layout

Layout adalah tata letak dari suatu elemen desain yang ditempatkan dalam sebuah bidang yang tujuannya mengatur desain supaya menjadi indah dan menarik. Layout sangat berperan penting dalam perancangan buku pedoman ejaan bahasa Indonesia. Pada perancangan ini menggunakan layout yang menarik disesuaikan dengan segmentasinya, yaitu peserta didik.

4. Konsep Perancangan Buku

a. Layout Buku

Pada desain buku informasi srabad ini, peneliti memfokuskan pada kejelasan alur tulisan sebuah informasi, dengan cara menggunakan layout yang sederhana, tetapi menarik sehingga alur keterbacaan jelas dan mudah untuk memahami informasi yang ingin disampaikan. Peneliti akan menggunakan Copy Heavy Layout adalah jenis tata letak yang mengutamakan pada bentuk copy writing/naskah, dengan kata lain komposisi layout-nya didominasi oleh penyajian teks (copy).

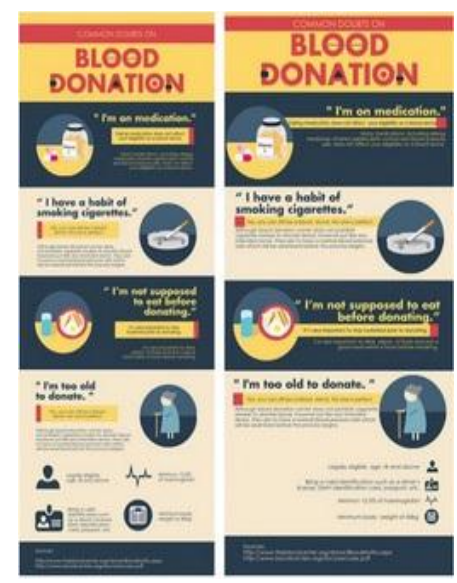

Gambar 1 Konsep Layout

Sumber: Slideshare, 2016, 23 Januari

b. Tipografi

Tipografi merupakan elemen penting dalam merancang desain, terutama layout buku. Tipografi harus mampu berkomunikasi dalam bentuk yang paling jelas dan terbaca. Tujuannya membuat nyaman pada saat membacanya, baik dalam jarak dekat maupun jarak jauh. Sehingga maksud dari arti tulisan tersebut tersampaikan dengan sangat baik secara visual. Peneliti menggunakan font Depalma.ttf dan font Letters for Learners.ttf sebagai dasar perancangan. Font Depalma.ttf digunakan pada judul buku dan judul tema pada isi buku dan font Letters for Learners.ttf untuk bagian French Title + editorial, publishing dan isi buku.

\section{A B C D E F G H I J K L M N O P Q R S T U V W X Y Z \\ Abcdefghijklmnopqrstuvw yz \\ $1234567890-=+$ ?!$$
\text { \#\&*( ) }
$$

Gambar 2 Font Depalma.ttf

Sumber: Dokumentasi pribadi 


\section{A B C D E F G H I J K L M N O P Q R S T U V W X Y Z \\ A b c defghijk lm nopqratuv x y z \\ $1234567890-=+$ ?! @ \# \&*( ) \\ Gambar 3 Font Depalma.ttf \\ Sumber: Dokumentasi pribadi}

c. Ilustrasi

Untuk rancangan buku ini, ilustrasi yang peneliti gunakan adalah ilustrasi gambar vektor dan foto. Ilustrasi digunakan sebagai penunjang visual.

d. Warna

Dalam penggunaan warna, peneliti memilih warna-warna seperti biru, oren, kuning, hijau dan cokelat seperti warna khas srabad Cirebon.

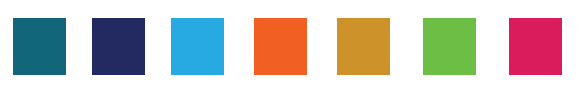

Gambar 4 Warna pada Buku

Sumber: Dokumentasi pribadi

5. Fungsi Buku Informasi Srabad

Sebagai referensi untuk menambah wawasan tentang budaya tradisi Cirebon, khususnya Srabad. Mengambil nilai moral seperti toleransi dan spiritual yang ada pada srabad.

\section{SIMPULAN}

Seni tradisi Cirebon mengandung daya spiritual. Dalam penciptaannya dibuat untuk sarana penyebaran agama Islam. Lambang-lambang budaya Hindu dan Islam digunakan dalam srabad. Unsur-unsur Hindu dengan tema-tema pewayangan, dimodifikasi menjadi Islami berupa untaian tulisan Arab dengan pesan ayat-ayat Alquran. Bentuk srabad ada yang menonjolkan tulisan Arab yang disertai dengan ornamen lokal seperti motif mega mendung dan wadhasan (batu karang). Kemudian kaligrafi dengan tulisan Arab dengan meminjam figur unsur rupa sebagai bentukan kaligrafinya, seperti semar. Yang menjadi daya tarik dari srabad adalah selain sebagai karya seni yang memiliki estetika, srabad juga menjadi sarana dakwah yang bermuatan magis religious yang dipercaya dapat membawa ketenangan jiwa. Bentuk srabad dalam masyarakat menghasilkan beberapa bentuk, seperti ukir kayu, batik namun yang cukup berkembang dan masih dibuat hingga sekarang adalah lukisan kaca.

Media yang dipilih adalah buku informasi karena dapat menyajikan data tentang seni tradisi yang ada di Cirebon, khususnya srabad secara rinci. Lebih spesifik dengan menampilkan gambar serta penjelasannya sehingga dapat menambah wawasan serta meningkatkan fokus dan konsentrasi.

\section{DAFTAR PUSTAKA}

Anto, P., Andrijanto M. S., dan Akbar T. (2017). Perancangan buku pedoman umum ejaan bahasa Indonesia sebagai media pembelajaran di sekolah. Jurnal Desain. 4(2), 92-99.

Budiono, K. (2002). Makna lukisan kaca Cirebon. Jurnal Seni Rupa dan Desain, 2(5), 1-12.

Choiriyah, R. (2014). Mendesain buku jajanan dan permainan popular era ' 80 'an sebagai identitas budaya. Jurnal Desain. 1(2), 126-141.

Fathurrohman. I. (2002). Lukisan kaca Cirebon, konfigurasi estetis multidimensi; napak tilas lukisan kaca Cirebon generasi pertama. Jurnal Al-Turas. 7(1), 39-56. 
Sucitra, I. G. A. (2015). Transformasi sinkretisma Indonesia dan karya seni Islam. Journal of Urban Society's Art, 2(2), 89-103.

Wulandari, Y. I. (2012). Analisis estetis lukisan kaca Cirebon tema Semar dan Macan Ali. jurnal tingkat sarjana bidang seni rupa, 1(1), 1-10.

Slideshare. (2016, 23 Januari). Berbagai jenis layout. Diakses dari https://www.slideshare.net/ributghost/berbagai-jenis-layout 